\begin{tabular}{|c|c|c|}
\hline \multirow{3}{*}{$\begin{array}{r}\text { Case Reports in } \\
\text { Gastroenterology }\end{array}$} & \multirow{2}{*}{\multicolumn{2}{|c|}{ Case Rep Gastroenterol 2018;12:453-456 }} \\
\hline & & \\
\hline & $\begin{array}{l}\text { DOI: } 10.1159 / 000492208 \\
\text { Published online: August 21, } 2018\end{array}$ & $\begin{array}{l}\text { () } 2018 \text { The Author(s) } \\
\text { Published by S. Karger AG, Basel } \\
\text { www.karger.com/crg }\end{array}$ \\
\hline & $\begin{array}{l}\text { This article is licensed under the } \\
\text { International License (CC BY-NC) } \\
\text { Usage and distribution for commer }\end{array}$ & $\begin{array}{l}\text { mons Attribution-NonCommerc } \\
\text { rger.com/Services/OpenAccessLi } \\
\text { guires written permission. }\end{array}$ \\
\hline
\end{tabular}

\title{
Colonic Malakoplakia: A Rare Finding in a Healthy Male
}

\author{
Rawad A. Yared ${ }^{a}$ Hussein A. Badran ${ }^{a}$ \\ Mohammed Hussein Kamareddine ${ }^{b} \quad$ Youssef Ghosn $^{\mathrm{b}} \quad$ Roula Bou Khalil ${ }^{\mathrm{c}}$ \\ Khaled El Ajamy ${ }^{d} \quad$ Camil Chouairy ${ }^{\mathrm{e}}$ Said G. Farhat ${ }^{\mathrm{a}}$ \\ ${ }^{a}$ Department of Gastroenterology, Saint George Hospital University Medical Center, \\ University of Balamand, Beirut, Lebanon; 'baint George Hospital University Medical \\ Center, Faculty of Medicine and Medical Sciences, University of Balamand, \\ Beirut, Lebanon; 'Department of Endocrinology, Saint George Hospital University Medical \\ Center, University of Balamand, Beirut, Lebanon; dDepartment of Gastroenterology, Saint \\ George Hospital University Medical Center, University of Balamand, Beirut, Lebanon; \\ eDepartment of Pathology, Saint George Hospital University Medical Center, University of \\ Balamand, Beirut, Lebanon
}

\section{Keywords \\ Malakoplakia · Gastrointestinal tract · Transverse colon}

\begin{abstract}
Malakoplakia is a rare chronic granulomatous disease that may affect many organs, including the lung, brain, adrenal glands, pancreas, bone, and the genitourinary tract. The gastrointestinal tract is the most common site of involvement outside of the urinary tract. Herein, we present a case of a 65-year-old male who presented with abdominal pain and unintentional weight loss. Physical examination findings were unremarkable, but colonoscopy revealed an isolated large, flat, soft, and pale lesion in the transverse colon. Histopathological examination of the lesion showed expansion of the lamina propria due to numerous lymphocytes, plasma cells, neutrophils, and polygonal cells. Von Kossa stain showed small intracytoplasmic basophilic granular inclusions, and these histiocyte cells showed numerous Michaelis-Gutmann bodies, findings considered as diagnostic features of colonic malakoplakia. This is a rare case of isolated malakoplakia of the transverse colon diagnosed on endoscopic specimens. The majority of reported cases have shown an association between systemic diseases and colorectal adenocarcinoma. In addition, most reported cases of colonic involvement have been in the rectum, sigmoid, and right colon.


Yared et al:: Colonic Malakoplakia: A Rare Finding in a Healthy Male

\section{Introduction}

Malakoplakia is a rare chronic granulomatous disease that may affect many organs, including the lung, brain, adrenal glands, pancreas, bone, and the genitourinary tract. The gastrointestinal tract is the most common site of involvement outside of the urinary tract $[1,2]$. With regard to the pathogenesis of malakoplakia, the disease is considered to be related to immunosuppression and/or infectious processes [3]. The treatment of Malakoplakia varies, ranging from antibiotic therapy to surgical resection [1]. Herein, we describe the case of a 65year-old male who presented for abdominal pain and unintentional weight loss and was found to have an incidental colonic malakoplakia. Endoscopy revealed the atypical finding of an isolated large and flat lesion in the transverse colon.

\section{Case Report}

A 65-year-old male presented with complaint of diffuse and colicky abdominal pain that had lasted for 6 months. He reported unintentional weight loss of about $4 \mathrm{~kg}$ (from $77 \mathrm{~kg}$ to $73 \mathrm{~kg}$, i.e., $5.2 \%$ weight loss) that had occurred over the previous 6-month period, with no change in bowel habits. The patient denied any use of immunosuppressive or chemotherapeutic drug, recurrent infections, malnutrition, or other associated medical conditions. Physical examination yielded no remarkable findings. The results of the complete blood count, electrolytes, carcinoembryonic antigen $(1.2 \mathrm{ng} / \mathrm{mL})$, liver chemistry, and function tests were within normal limits. HIV serology was negative. Computed tomography scan of the abdomen and pelvis, with intravenous and oral contrast, produced normal findings. Colonoscopy revealed a 3-cm large, flat, soft, and pale lesion in the transverse colon (Fig. 1a). Histopathological examination of the lesion using Von Kossa stain revealed expansion of the lamina propria due to numerous lymphocytes, plasma cells, neutrophils, and polygonal cells. The latter cells showed small intracytoplasmic basophilic granular inclusions; these cells were histiocytes and showed numerous Michaelis-Gutmann bodies (Fig. 1b), findings considered as diagnostic features of colonic malakoplakia [3]. As a treatment option, the antibiotic ciprofloxacin was used and was successful.

\section{Discussion}

Malakoplakia, a term derived from the Greek adjectives "malakos" (soft) and "plaka" (plaque), describes a rare chronic granulomatous condition. Initially described by Michaelis and Gutmann in 1902 [3], the disease is mainly diagnosed according to the characteristic feature of accumulated histiocytes having cytoplasmic inclusions, known as Michaelis-Gutmann bodies [4]. The majority of reported cases $(\sim 75 \%)$ involve the genitourinary tract [5]. The second most common site is the gastrointestinal tract, and the majority of these cases involve the rectum, sigmoid, and right colon $[1,2]$. The remaining cases affect a diverse range of organs, including the lung, brain, adrenal glands, lymph node, tonsils, skin, abdominal wall, liver, pancreas, bone, and the retroperitoneum [6]. To date, the etiology of malakoplakia remains unknown. However, several pathogenic mechanisms have been proposed, such as infection, immunosuppression (immune deficiency disorders and organ transplantation), systemic illness, neoplasia, and genetic disorder. Intriguingly, most of the cases reported have shown an association between systemic diseases and colorectal adenocarcinoma [2, 7-9]. 
Clinical manifestations of colonic malakoplakia are very diverse, from asymptomatic to the presence of diarrhea, abdominal pain, rectal bleeding, intestinal obstruction, vomiting, malaise, fever, and constipation [6]. Colonoscopic examination generally reveals the following 3 patterns of the disease (possibly but not always concurrent): isolated rectosigmoid involvement, in which lesions appear as yellowish plaques that may be sessile, polypoid, and ulcerated; strictured colonic lumen and intestinal fistulas, suggesting a concomitant diagnosis of cancer or Crohn's disease; and diffuse colonic involvement, a characteristic of immunosuppressed patients. The presence of focal lesions may be associated with an adenomatous polyp or cancer [10].

Colonic malakoplakia can resemble other diseases, both in gross and histological findings. The endoscopic deferential diagnoses for colonic malakoplakia include malignancies, miliary tuberculosis and Crohn's disease [6]. By pathology, colonic malakoplakia could appear similar to Whipple's disease, ceroid colonic histiocytosis, Wolman's disease [11], Chediak-Higashi syndrome, sarcoidosis and other granulomas, and histiocytic storage diseases [6].

For the patient described in this case report, we performed a careful history review and physical examination. There was no history or sign of immunosuppressive or chemotherapeutic drug use, recurrent infections, malnutrition, or other associated medical conditions. Since an infectious etiology was considered likely, ciprofloxacin (a broad-spectrum antibiotic capable of penetrating macrophages) was administered [12] and effective. The long-term treatment (500 mg twice daily) was intended as an add-on to prevent recurrence and treat any other possible lesions not seen on colonoscopy.

This case of isolated malakoplakia in the colon of a generally healthy male with no obvious associated disease illustrates the rarity of this presentation and the need for a high level of clinical suspicion to diagnose the disease.

\section{Statement of Ethics}

The patient provided written informed consent for the analysis and publication of the case-related information.

\section{Disclosure Statement}

The authors declare they have no conflicts of interest related to this publication.

\section{References}

1 Cipolletta L, Bianco MA, Fumo F, Orabona P, Piccinino F. Malacoplakia of the colon. Gastrointest Endosc. 1995 Mar; 41(3):255-8.

2 McClure J. Malakoplakia of the gastrointestinal tract. Postgrad Med J. 1981 Feb;57(664):95-103.

3 Han SH, Joo M, Chang S, Kim HS. Malakoplakia affecting the umbilical cord. J Pathol Transl Med. 2015 Mar;49(2):177-9.

4 Hyun KH, Shin HD, Kim DH. Malakoplakia in a healthy young female patient. Korean J Intern Med (Korean Assoc Intern Med). 2013 Jul;28(4):475-80.

5 Long JP Jr, Althausen AF. Malacoplakia: a 25-year experience with a review of the literature. J Urol. 1989 Jun;141(6):1328-31.

6 Yousef GM, Naghibi B, Hamodat MM. Malakoplakia outside the urinary tract. Arch Pathol Lab Med. 2007 Feb;131(2):297-300. 
Yared et al.: Colonic Malakoplakia: A Rare Finding in a Healthy Male

7 Elie H, Maupin JM, Mandard JC. [Malacoplakia in a rectal adenocarcinoma. Review of the literature. Apropos of a case]. Ann Pathol. 1983 Dec;3(4):333-6.

8 Karasavvidou F, Potamianos SP, Barbanis S, Stathakis E, Psychos A, Kapsoritakis AN et al. Malakoplakia of the colon associated with colonic adenocarcinoma diagnosed in colonic biopsies. World J Gastroenterol. 2007 Dec;13(45):6109-11.

9 Sandmeier D, Guillou L. Malakoplakia and adenocarcinoma of the caecum: a rare association. J Clin Pathol. 1993 Oct;46(10):959-60.

10 Feldman M, Lawrence S, Friedman MD, Lawrence J, Brandt MD. Sleisenger and Fordtran's Gastrointestinal and Liver Disease. 10th ed. Philadelphia: Elsevier; 2016.

11 Perez-Atayde AR, Lack EE, Katz AJ, Geha RS. Intestinal malakoplakia in childhood: case report and review of literature. Pediatr Pathol. 1983 Jul-Sep;1(3):337-43.

12 van Furth R, van't Wout JW, Wertheimer PA, Zwartendijk J. Ciprofloxacin for treatment of malakoplakia. Lancet. 1992 Jan;339(8786):148-9.
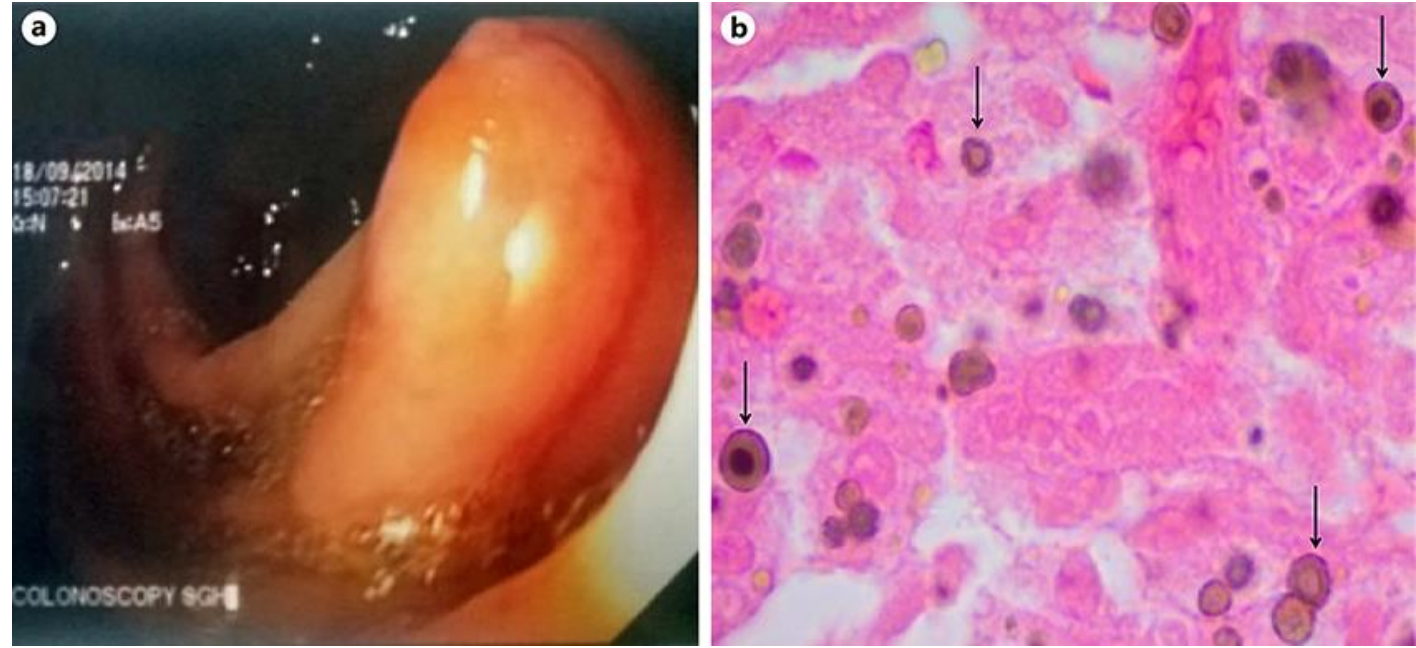

Fig. 1. Colonoscopy and histologic findings. a A 3-cm lesion was detected in the transverse colon. b Von Kossa stain of the lesion (original magnification $\times 800$ ) showing histiocytes with numerous Michaelis-Gutmann bodies (arrows). 